\title{
THE MECHANISM OF EFFORT SYNCOPE IN PRIMARY PULMONARY HYPERTENSION AND CYANOTIC CONGENITAL HEART DISEASE
}

BY

\author{
SHEILA HOWARTH AND J. B. LOWE \\ From the Institute of Cardiology, National Heart Hospital \\ Received September 25, 1952
}

Loss of consciousness on exertion is common in primary pulmonary hypertension, and the diagnostic value of this symptom has recently been emphasized by Dressler (1952). Yet effort syncope was recorded in only one-fifth of the 39 reported cases collected and reviewed by Dresdale et al. (1951). Some patients with cyanotic congenital heart disease also complain of fainting attacks occurring after exertion and one such case was reported as early as 1784 by William Hunter. There has been considerable speculation as to the mechanism of syncope in both these groups, and the purpose of this paper is to present records obtained during attacks of unconsciousness produced by effort in primary pulmonary hypertension, and to report observations made during exercise in congenital heart disease.

\section{Material AND Methods}

Investigations are reported on two cases of primary pulmonary hypertension and seven cases of congenital heart disease. The clinical diagnosis was supported by cardiac catheterization and confirmed at necropsy in both those with primary pulmonary hypertension. Two cases of Fallot's tetralogy were investigated, in whom angiocardiography and cardiac catheterization supported the clinical diagnosis. The remaining five all had pulmonary hypertension, associated in four with patent ductus arteriosus and in one with ventricular septal defect. Cardiac catheterization showed that the pulmonary hypertension was severe in all five, and in every case the catheter entered the systemic circulation at the site of the shunt.

Capacitance manometers (Hansen, 1949) were used to obtain continuous brachial arterial pressure records during standing running, which was performed in every case, the outstretched arm being supported at approximately heart level. The blood pressure records showed the usual interference patterns during exercise. In two patients, recumbent during cardiac catheterization, simultaneous right heart and brachial artery pressure tracings were taken during and after exercise of the legs against a resistance.

\section{Results in Primary Pulmonary Hypertension}

Case 1. This boy gave a history of attacks of unconsciousness brought on by considerable effort during the previous year; at the time of observation he was in congestive heart failure and had a raised venous pressure and œdema. Standing running for 46 seconds caused extreme dyspnœa that prevented further exertion, but on this occasion no syncopal attack was induced. The systemic blood pressure rose during effort and had returned to the control level approximately one minute after exercise was stopped.

Case 2. This young woman complained of increasingly frequent and severe attacks of effort syncope during the previous nine months. The brachial artery pressure during and after standing running is shown in Fig. 1. During exertion there was a decrease in both systolic and diastolic 
pressures: after exercise, both fell and the pulse pressure diminished. During the period of falling blood pressure the patient was supported in the erect position and, after complaining of dizziness, lost consciousness. Bradycardia occurred at the end of the record when the blood pressure was at its lowest. On a subsequent occasion, an electrocardiogram was taken before and after exercise.

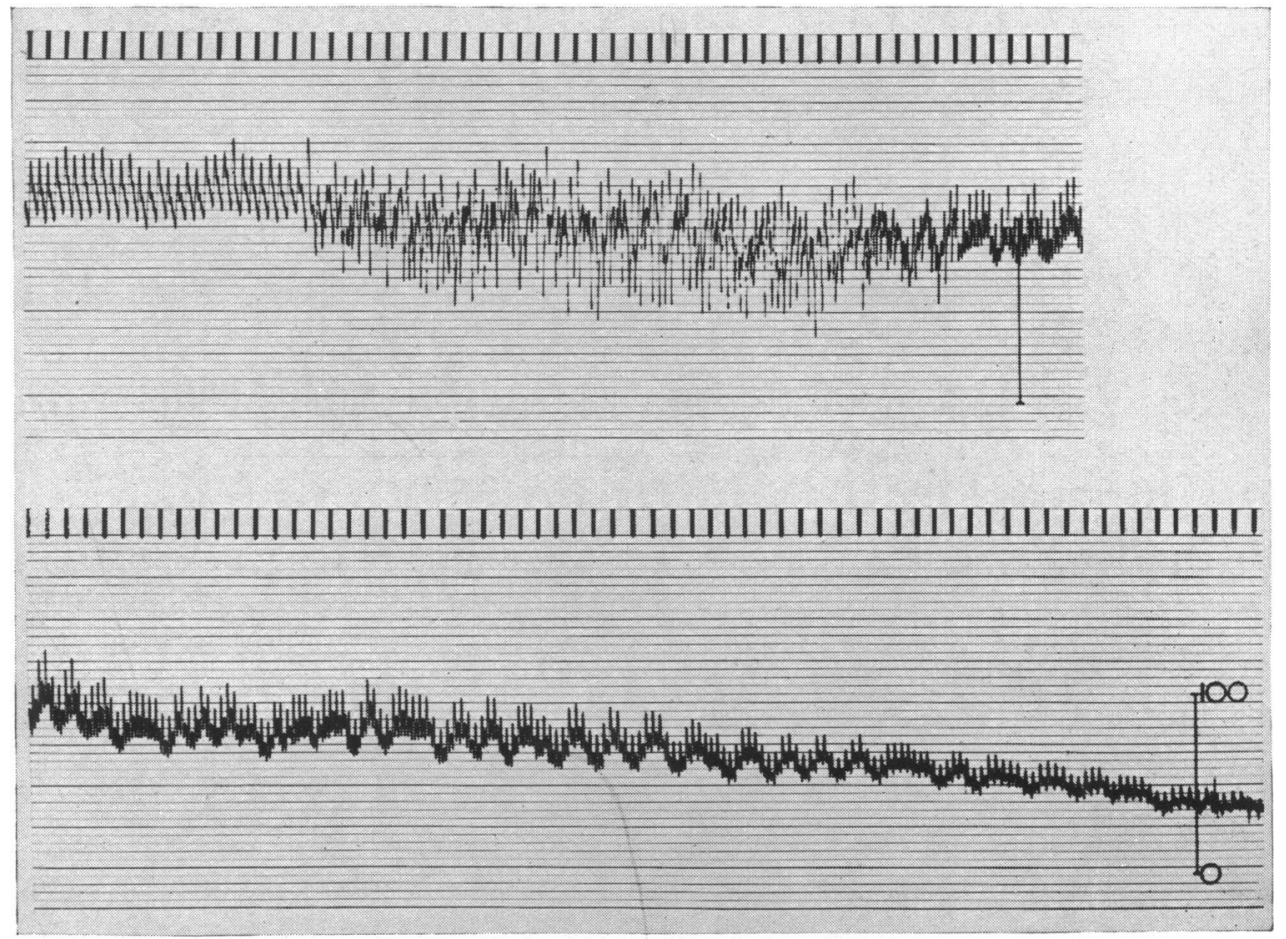

Fig. 1.-Case 2. Syncopal attack in primary pulmonary hypertension. Continuous brachial arterial pressure record before, during, and after standing running (indicated by interference on pressure record). Time scale (top) in this and subsequent records in seconds. Calibrations in $\mathrm{mm}$. $\mathrm{Hg}$.

The tracing (Fig. 2) shows the tachycardia immediately after effort, and the onset of sinus bradycardia some $1 \frac{1}{2}$ minutes later when the patient complained of faintness and when the blood pressure had presumably fallen to a low level. In an attempt to elucidate the mechanism of the attacks, further observations were made during cardiac catheterization (Fig. 3). After exercise, brachial arterial pressure fell gradually and loss of consciousness resulted as before. Bradycardia occurred when the mean pressure had reached about $30 \mathrm{~mm}$. Hg. The pulmonary artery pressure rose steeply on effort; and at the end of exercise, when the catheter had slipped back into the right ventricle, the systolic pressure in this chamber was approximately $140 \mathrm{~mm}$. $\mathrm{Hg}$. During the time when the systemic arterial pressure was falling, the pulse pressure in the right ventricle decreased and the diastolic pressure rose by 10 to $15 \mathrm{~mm}$. $\mathrm{Hg}$. These results are consistent with acute failure of the right ventricle. Systemic blood pressure, right ventricular systolic and pulse pressures, and heart rate then increased spontaneously. Recovery was, however, interrupted by a period of grossly disordered rhythm, accompanied by cessation of respiration, before all readings returned to normal.

Results in Congenital Heart Disease

Fallot's Tetralogy. Case 3. This boy with Fallot's tetralogy squatted when breathless but did not give a history of effort syncope. Resting arterial oxygen saturation was 74 per cent. Although 

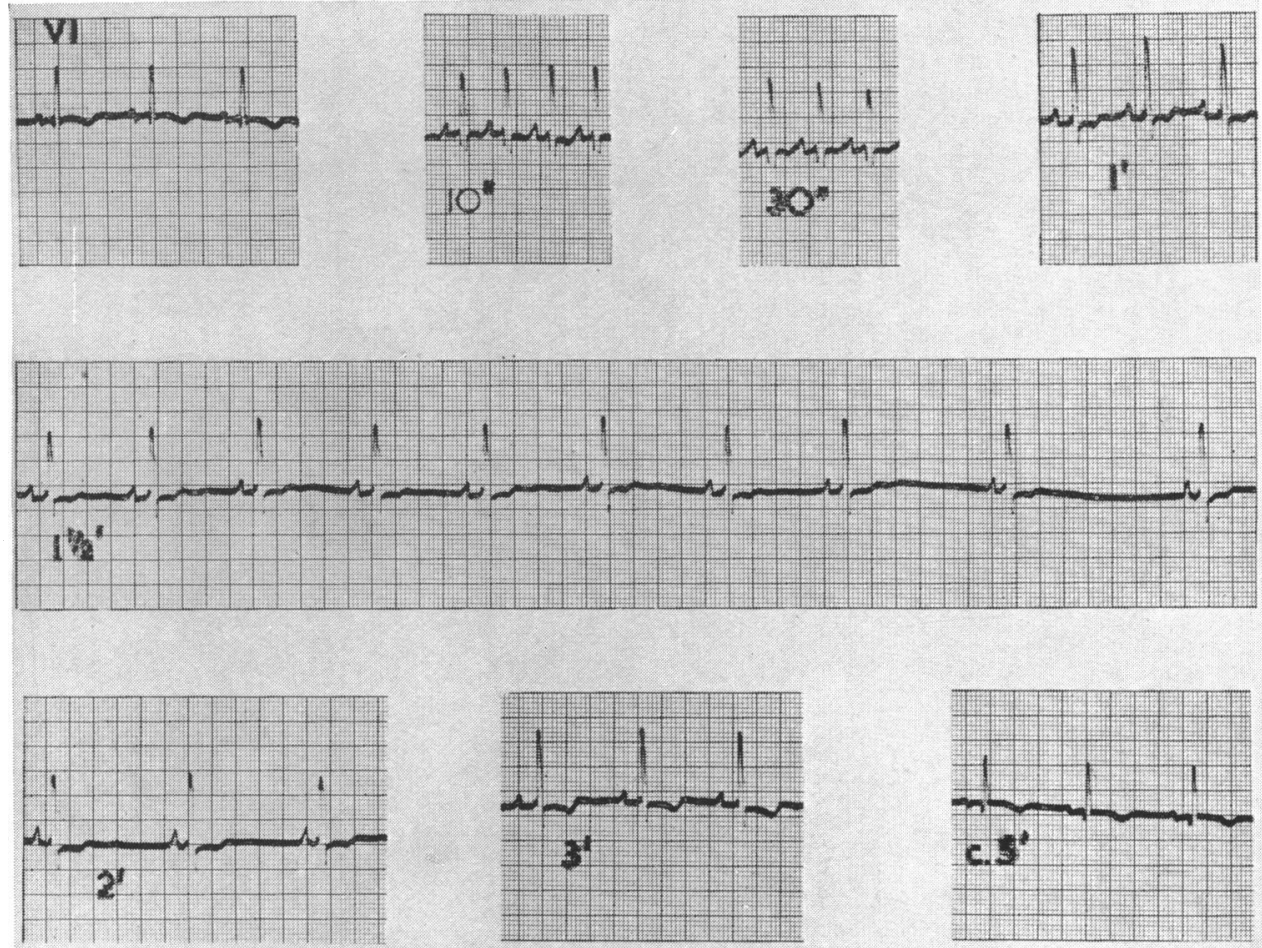

Fig. 2.-Case 2. Electrocardiogram (lead Vl) taken before and at stated intervals after exercise.

standing running was continued to the limit of his endurance and resulted in extreme dyspnœa and a considerable increase in cyanosis, no fall in systemic pressure was seen either during or after exercise.

Case 4. Cyanosis at rest was inconspicuous in this patient with Fallot's tetralogy, but ever since infancy exertion had caused cyanosis and frequently loss of consciousness. Standing running induced a syncopal attack (Fig. 4). Systolic and diastolic brachial artery pressures rose during effort but in the period after exercise there was a gradual decline in both, together with a decrease in pulse pressure. During the last part of the observation the patient had to be supported on account of dizziness, and he lost consciousness some five minutes after the end of exertion when the mean blood pressure was just over $50 \mathrm{~mm}$. $\mathrm{Hg}$. Bradycardia appeared at the end of the tracing but the record at this point was unsatisfactory and is not shown. It is noteworthy that the patient was still markedly cyanosed and also dyspnœic when loss of consciousness supervened.

Patent Ductus Arteriosus with Pulmonary Hypertension. Case 5. This young woman gave a clear history of effort syncope. Strenuous exercise was followed by severe breathlessness and chest pain of some two minutes duration, and she would then sometimes lose consciousness. Syncopal attacks had occurred during the previous two years and had been most frequent in the summer months. She was not cyanosed at rest, when arterial oxygen saturation was 90 per cent, but had been told that she became blue on effort. Although standing running not only resulted in severe dyspnca and striking cyanosis but also caused her to complain of faintness, there was no fall in systemic blood pressure (Fig. 5). During cardiac catheterization, exercise again failed to induce a syncopal attack. Both systemic and pulmonary arterial pressures rose during exertion, returning to control levels afterwards.

Of three other similar patients (Cases 6, 7, and 8) with patent ductus arteriosus and pulmonary 


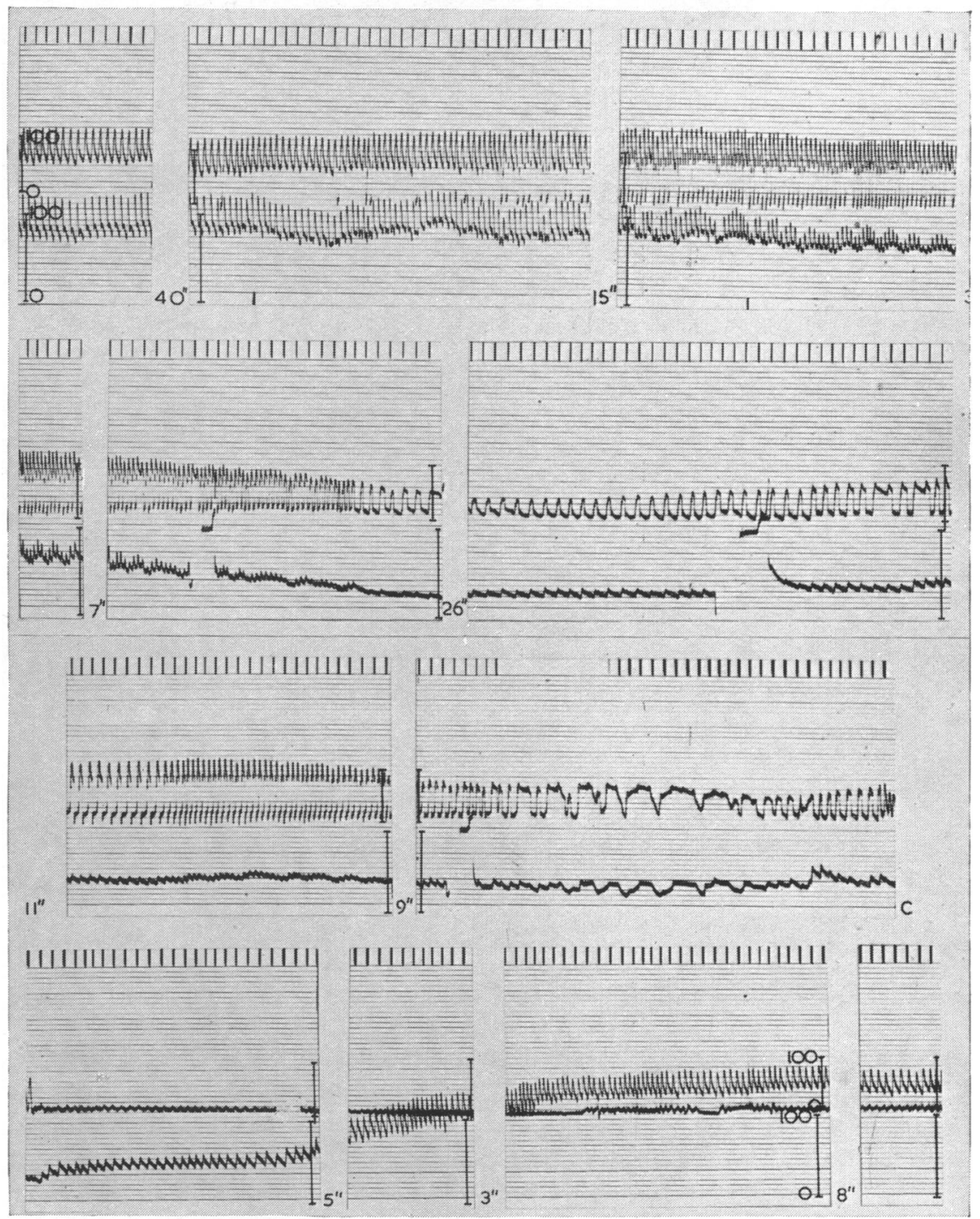

FIG. 3.-Case 2. Continuous record of syncopal attack induced during cardiac catheterization. Beginning and end of exercise marked by signals at bottom of tracing. Upper record: pressure in (a) pulmonary artery (first two strips) (b) right ventricle (six strips) and (c) right atrium (remainder of tracing). Lower record: brachial artery pressure. Breaks in continuous record indicated by figures at bottom of tracing. For full description, see text.

hypertension sufficiently severe to cause shunt reversal and cyanosis on exertion, only one gave a history of faintness after effort. This had occurred when strenuous effort had caused extreme breathlessness and cyanosis. The response of the brachial artery pressure to vigorous standing running was observed in all three: in none did faintness or dizziness result, and in none was there a fall in pressure either during or after exercise.

Ventricular Septal Defect with Pulmonary Hypertension. Case 9. This patient had suffered from transient attacks of giddiness and cyanosis on effort for seven years, and for four years syncopal 


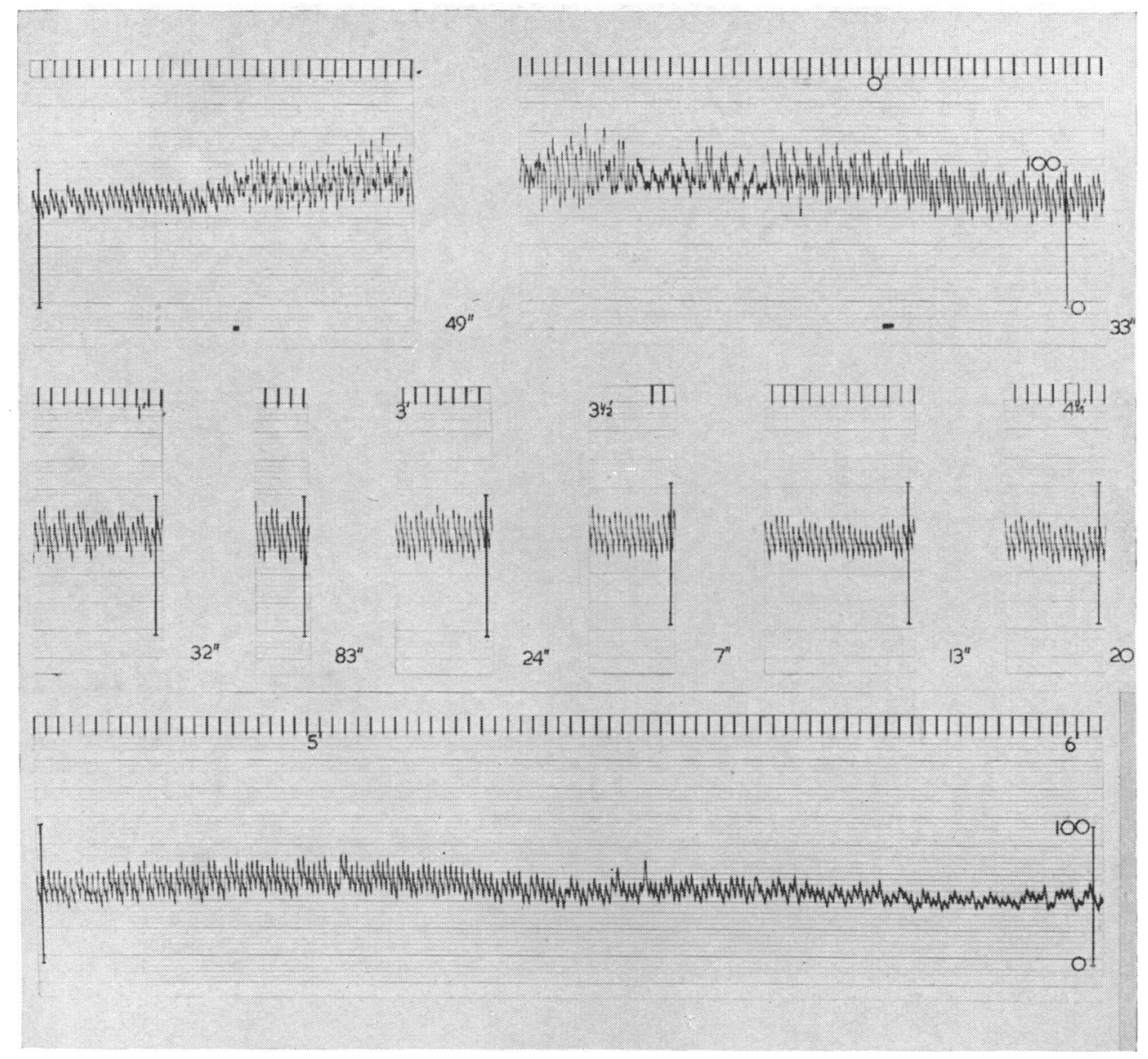

FIG. 4.-Case 4. Fallot's tetralogy. Brachial arterial blood pressure record during a syncopal attack induced by exercise. Figures below time marker are minutes after exercise. Consciousness was lost about 5 minutes after exercise ended.

attacks had occurred after severe exertion. Brachial artery pressure was recorded during two periods of standing running. On the first, moderate exercise for two minutes resulted in cyanosis and a transient fall in diastolic pressure during the first ten seconds after exertion (Fig. 6a). On the second occasion more strenuous effort was undertaken for approximately $3 \frac{1}{4}$ minutes (Fig. 6b). During exertion the diastolic pressure fell but there was no decrease in pulse pressure. About 30 seconds after exercise the diastolic pressure started to rise again but had not returned to its initial level three minutes later. During exertion arterial oxygen saturation decreased from the resting level of 92 to 51 per cent. Dyspnœa persisted for some minutes afterwards but the patient did not feel faint.

\section{Discussion}

In conditions where cardiac output is relatively fixed, peripheral vasodilatation induced by exercise might be expected to cause a fall in systemic blood pressure. This should occur towards or at the end of exercise when vasodilatation, especially of muscle vessels, is maximal. The syncopal attacks of primary pulmonary hypertension might, on a priori grounds, be explained in this manner, since the high pulmonary resistance might limit the increase in cardiac output on exercise. 


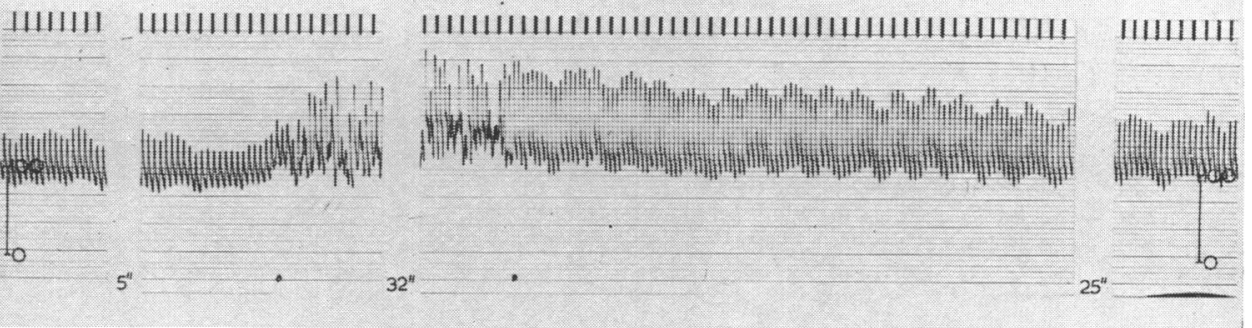

Fig. 5.-Case 5. Pulmonary hypertension with patent ductus arteriosus. Patient became cyanosed and complained of dizziness after effort: no fall in blood pressure was recorded.

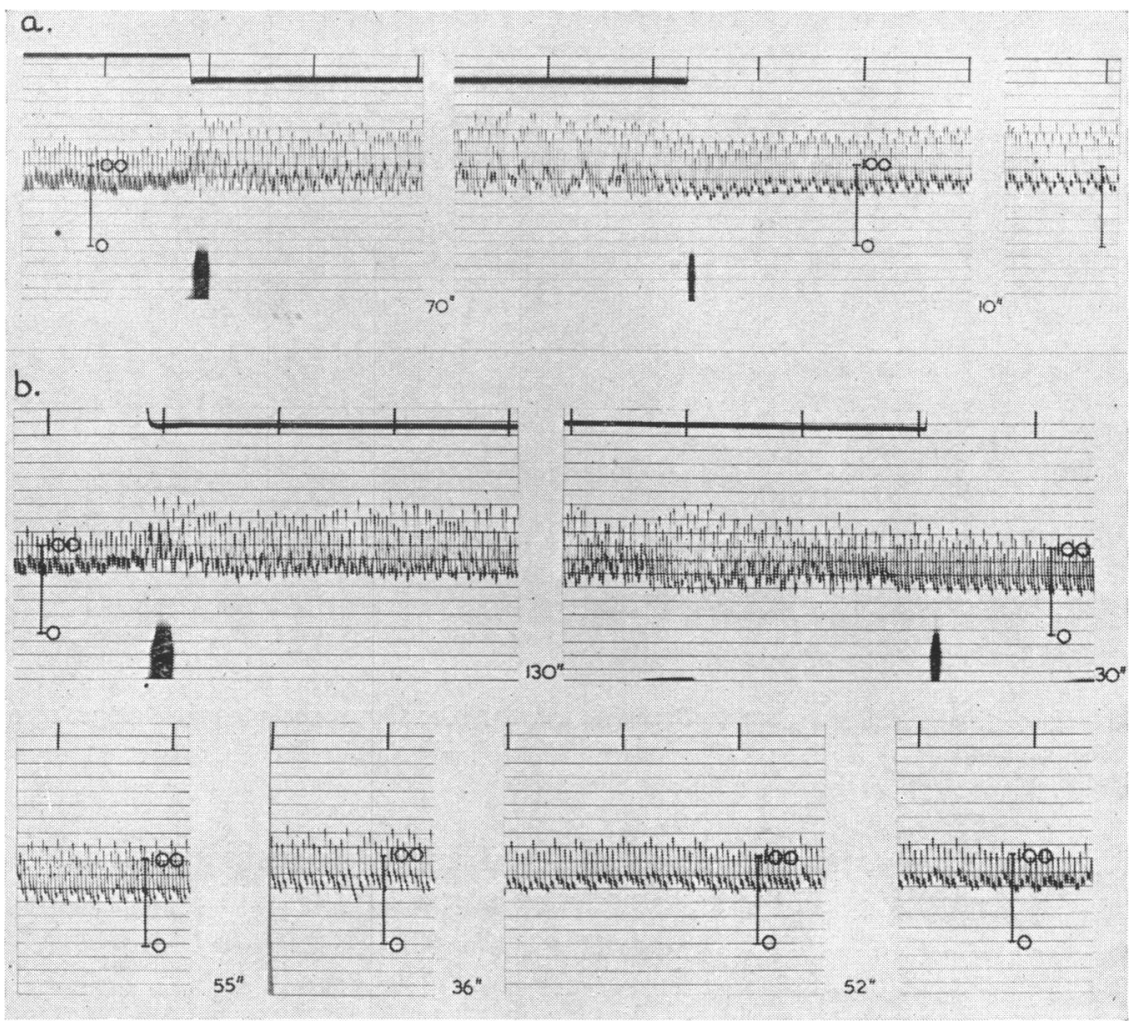

Fig. 6.-Case 9. Pulmonary hypertension and ventricular septal defect. (a) Exercise for two minutes resulted in cyanosis with transient fall in blood pressure. (b) More strenuous exercise caused a symptomless fall in diastolic pressure with marked cyanosis. Time scale in both records is 10 seconds.

Continuous blood pressure records taken during effort syncope in this condition, however, show that the fall in systemic pressure leading to unconsciousness is gradual and progressive from the end of exercise. Simultaneous records of right heart and systemic blood pressures during an attack show acute right heart failure with diminishing right heart output to be the cause of the falling blood pressure. The steep rise in pulmonary arterial pressure on exercise is presumably the main factor precipitating failure of the right ventricle.

In the cases reported here, syncope did not occur during exercise, but followed after a varying 
period, and the clinical observations correlated well with the observed blood pressure records, which showed the hypotension to be gradual and progressive. In the more severe or terminal type of case, however, it might be expected that the amount of exercise required to induce acute right heart failure would be less. Such a case was observed two days before death, when foot movements resulted in a steady and continuous fall in the recorded blood pressure, leading to syncope after one minute while exercise was still in progress.

The pallor, low blood pressure, and bradycardia seen during this form of syncope resemble the vasovagal faint, but the mechanism is different. In vasovagal fainting, sudden hypotension results from a fall in peripheral resistance due to muscle vasodilatation, while cardiac output remains relatively unchanged (Barcroft et al., 1944). Conditions that cause vasovagal fainting are those in which the filling pressure of the heart is reduced (Brigden et al., 1950). In the effort syncope of primary pulmonary hypertension the diastolic pressure rises on the right side of the heart. No studies have yet been made on the peripheral circulation in the latter group.

Bradycardia occurs when the blood pressure reaches low levels both in the vasovagal and exertional faints. It has been suggested by Dressler (1952) that in pulmonary hypertension this is a reflex from the pulmonary artery, where a rise in pressure has been shown experimentally in animals to cause cardiac slowing (Parin, 1947; Aviado et al., 1951). In vasovagal fainting where pulmonary arterial pressure falls (Howarth and Lowe, unpublished observations) and during syncope in Fallot's tetralogy, this explanation would appear unlikely. Certainly vasovagal fainting may be induced in the atropinized subject without alteration in heart rate (Lewis, 1932; Howarth, 1952). It is suggested that bradycardia in both types of fainting is secondary to the low blood pressure state.

In cases where a shunt existed and a history of syncope was present, resting arterial oxygen saturation was relatively normal. On effort, considerable cyanosis was either observed or measured. A sudden fall in arterial oxygen tension may cause loss of consciousness in the normal subject, with fall in blood pressure, bradycardia, and muscle vasodilatation (Anderson et al., 1946). A sudden decrease in arterial oxygen saturation may well be a factor in the mechanism of syncope when a right to left shunt is present.

\section{SUMMARY}

Blood pressure records were obtained in cases of primary pulmonary hypertension and Fallot's tetralogy during induced syncope after exertion. Blood pressure fell gradually and not precipitously after exercise. Sinus bradycardia and loss of consciousness occurred when the systemic pressure reached low levels.

A syncopal attack was induced in a case of primary pulmonary hypertension during cardiac catheterization. As the systemic pressure fell, the pulse pressure in the right ventricle decreased with a rise in the diastolic pressure.

These results are compatible with acute failure of the right ventricle.

Four cases of pulmonary hypertension with patent ductus arteriosus were exercised; no syncopal attack was induced. One case of pulmonary hypertension with patent interventricular septum exhibited a symptomless fall in systemic diastolic pressure after exercise, associated with considerable cyanosis.

It is suggested that sudden decrease in arterial oxygen saturation may be a factor causing loss of consciousness in cases with a right to left shunt.

We are indebted to Mr. J. G. Davies for technical assistance. The cases studied were under the care of the physicians to the National Heart Hospital. 


\section{REFERENCES}

Anderson, D. P., Allen, W. J., Barcroft, H., Edholm, O. G., and Manning, G. W. (1946). J. Physiol., $104,426$.

Aviado, D. M., Li, T. H., Kalow, W., Schmidt, C. F., Turnbull, G. L., Peskin, G. W., Hess, M. E., and Weiss, A. J. (1951). Amer. J. Physiol., 165, 261.

Barcroft, H., Edholm, O. G., McMichael, J., and Sharpey-Schafer, E. P. (1944). Lancet, $1,489$.

Brigden, W. W., Howarth, S., and Sharpey-Schafer, E. P. (1950). Clin. Sci., 9, 79.

Dresdale, D. T., Schultz, M., and Michton, R. J. (1951). Amer. J. Med., 11, 686.

Dressler, W. (1952). Amer. J. med. Sci., 223, 131.

Hansen, A. Tybjaerg (1949). Pressure Measurement in the Human Organism. Teknisk Forlag, Copenhagen.

Howarth, S. (1952). Shock and Circulatory Homeostasis. Green, H. D., Editor. Trans. 1st. Conf. New York, Josiah Macy Jr. Foundation, 1951 (p. 123).

Hunter, W. (1784). Med. Obs. Soc. Physicians, Lond., 6, 299.

Lewis, T. (1932). Brit. med. J., 1, 873.

Parin, V. V. (1947). Amer. J. med. Sci., 214, 167. 